\title{
DUAS CORREÇÕES À EPISTEMOLOGIA DE POPPER
}

\author{
POPPER'S EPISTEMOLOGY: TWO CORRECTIONS
}

\author{
REMI SCHORN ${ }^{1}$ \\ Universidade Estadual do Oeste do Paraná (Unioeste) - Brasil \\ remirs@hotmail.com
}

RESUMO: Este artigo discute duas concepções relativas a dois problemas filosóficos e apresenta formulações teóricas mais compatíveis com as demais dimensões da proposta epistemológica de Popper. O primeiro problema é: o conhecimento corresponde ao seu conteúdo? Mostramos que a concepção de verdade correspondencial, defendida pelo autor, não é a mais adequada e que uma concepção coerentista falibilista, articulada com uma ontologia relacional, é mais apta ao sistema teórico de Popper. O segundo problema é: a totalidade do existente pode ser apreendida por teorias científicas ou abordagens teóricas dessa ordem guardam, necessariamente, elementos metafísicos? Sustentar-se-á que a concepção de demarcação entre ciência e não ciência é impeditiva à constituição de uma cosmologia consequente, por fracionar o que a intuição criativa conjectural projeta como racionalidade capaz de aumentar a crítica objetiva às teorias vigentes e desafiar a racionalidade estabelecida nos programas de pesquisa. Aqui a deficiência da epistemologia popperiana será corrigida.

PALAVRAS-CHAVE: Cosmologia. Empirismo. Falibilismo. Metafísica. Coerência.

ABSTRACT: This article discusses two conceptions concerning two philosophical problems and presents theoretical formulations more compatible with the additional dimensions of Popper's epistemological proposal. The first problem is: does knowledge correspond to his notion of content? We show that the real correspondence theory of truth, defended by the author, is not the most appropriate and that a notion of coherent fallibilism, articulated with a relational ontology, is more suitable to the theoretical system of Popper. The second problem is: can the totality of existents be grasped by scientific theories or theoretical approaches that this order contains, necessarily, metaphysical elements? It will be maintained that the conception of demarcation between science and non-science is an impediment to the establishment of a consequent cosmology by fractionating the creative intuition conjectural designs as rationality capable of magnifying objective criticism theories and by challenging coherency established in research programs. Here, the Popperian epistemology deficiency will be corrected.

KEYWORDS: Cosmology. Empiricism. Fallibilism. Metaphysics. Coherence.

\section{INTRODUÇÃO}

Esta pesquisa investiga as respostas que podem ser extraídas da teoria popperiana para dois problemas filosóficos: a) a correspondência entre o

\footnotetext{
${ }^{1}$ Professor da Universidade Estadual do Oeste do Paraná (Unioeste).
} 
conhecimento e seu conteúdo referencial; b) a possibilidade de uma cosmologia ${ }^{2}$ científica. Nos dois casos, as concepções do autor não nos satisfazem, apesar de sua originalidade e riqueza racional. Substitutivamente a elas, são apresentadas formulações teóricas que se pretendem mais adequadas do que as originalmente propostas por Popper. Pretende-se, com isso, compatibilizar a epistemologia popperiana com os demais aspectos de sua filosofia. Relativamente ao primeiro problema, mostramos que a concepção de verdade correspondencial não é a mais adequada e que deve ser substituída por uma concepção coerentista falibilista, articulada com uma ontologia relacional propensitiva. ${ }^{3}$ No que se refere ao segundo problema, o da cientificidade de uma cosmologia, sustentar-se-á que não somente questões cosmológicas padecem do prejuízo trazido pela demarcação entre ciência e não ciência. A demarcação é impeditiva tanto de uma cosmologia consequente, por fracionar as relações que a intuição criativa conjectural estabelece, quanto é obtusa à racionalidade capaz de aumentar a crítica objetiva às teorias vigentes e desafiar epistemologicamente a racionalidade estabelecida nos programas de pesquisa.

O subsídio que permite constituir referencial teórico para enfrentar nosso desafio de corrigir Popper remete ao embate deste filósofo com alguns de seus críticos. Foi no âmbito das respostas a tais oposições que ele inaugurou uma nova filosofia, mais crítica, mais racional e mais objetiva. Seu falibilismo se aprofundou e seu empirismo construtivista venceu o embate com o positivismo lógico e mostrou a inevitabilidade de uma ontologia para uma concepção epistemológica relevante. Permaneceu, contudo, uma incongruência entre a consequência mais relevante desse pensamento, de que à filosofia cabe discutir os problemas da cosmologia, e a sustentação da demarcação e da verdade correspondencial. $O$ presente trabalho tem a pretensão de superar essa deficiência do racionalismo popperiano. Para tanto é imperativo lembrar que Hume ${ }^{4}$ sustentou não ser a relação causal uma conexão necessária no mundo físico, pois nem a razão nem os sentidos a alcançam, ela descreve sentimento de crença e não relação lógica, assim, ele subverteu a validade da indução. Kant, ${ }^{5}$ por sua vez, distinguiu a capacidade racional de produção de conhecimento objetivo da livre especulação metafísica e, assim, estabeleceu as condições para a demarcação. Kant reconheceu os limites da

\footnotetext{
2 Em Popper, a cosmologia trata do "problema de compreender o mundo - inclusive nós próprios e nosso conhecimento como parte do mundo" (POPPER, 2002, p. 535).

${ }^{3}$ Popper (2000a, p. 99) entende a ideia de propensões como "uma generalização da ideia de força - ou talvez como uma alternativa à ideia de força - sobretudo porque a ideia de força a princípio também foi vista com desconfiança por físicos racionalistas que, com razão, a denunciaram como oculta e metafísica. Mas desde então aprendemos (ou espero que tenhamos aprendido) que a ciência explica o conhecido pelo desconhecido, e o mundo visível por um mundo invisível e hipotético; (Newton nunca se sentiu muito feliz com a ideia de força de atração; Henrich Hertz tentou passar sem ela e o mesmo fez Einstein). Assim, da mesma maneira, podemos habituar-nos à ideia de propensões."

4 "Já observei que não há um só caso em que a conexão última entre os objetos pudesse ser descoberta por nossa razão ou por nossos sentidos, e que somos incapazes de penetrar tão profundamente na essência e estrutura dos corpos a ponto de perceber o princípio que fundamenta sua influência mútua” (HUME, 1978, p. 697).

5 Kant tratou de distinguir os conhecimentos racionais dos demais conhecimentos pela crítica filosófica. Concebeu a metafísica no âmbito do problema geral da razão, com juízos que interrogados constituem uma nova ciência, um sistema completo da filosofia da razão. Para ele "a razão só compreende o que ela mesma produz segundo seu projeto" (1929, XIII).
} 
razão e concebeu nossa apreensão da realidade como uma representação não verdadeira, por meio da qual o mundo se mostra ao entendimento. A relação entre Hume e Kant é evidente por ambos terem feito do ceticismo seu escudo contra a razão dogmática e, assim, instituído a crítica como método para desvendar as relações que conformam as apreensões teóricas do mundo. Esse ceticismo, presente em Hume e Kant, aparece também em Popper que não se limitou a transformar a filosofia do conhecimento de Kant em epistemologia, mas preocupou-se com inúmeros aspectos do entendimento humano, tanto concernentes à ciência, como à política e à ética e sustentou que os verdadeiros problemas filosóficos estão sempre ligados à teoria do conhecimento e, ao mesmo tempo, à cosmologia. Ele incorporou, entretanto, os ensinamentos de Gödel ${ }^{6}$ de que ou há incompletude ou há inconsistência nos sistemas teóricos e, por isso, considerou a crítica racional como sinônimo de filosofia, capaz de mostrar os limites dos sistemas. Popper fez uma nova revolução copernicana, aos moldes de Kant, mas para completar a tarefa kantiana. Enquanto Kant concebeu nossas ideias não como orientadas pelo mundo e sim este orientado por elas, Popper entendeu que o avanço em direção à verdade não pode prever que o mundo se comporte conforme as teorias, antes, que estas sejam falsificadas e corrigidas incansavelmente. Segundo Popper (2002a, p. 25) “[...] as teorias são invenções nossas, ideias nossas, o que foi claramente percebido pelos epistemólogos idealistas". Considerando que o grau de acerto de nossas invenções é limitado, apenas "[...] algumas dessas teorias são tão ousadas que podem entrar em conflito com a realidade: são essas as teorias testáveis da ciência [...] aí sabemos que há uma realidade: algo que nos pode informar que as nossas ideias estão erradas. É por isso que o realista tem razão" (2002a, p. 25). O que Popper ressalta é que o nosso intelecto falha seguidamente na tarefa de impor as ideias ao mundo. Assim, seu critério de cientificidade afirma que se deve aceitar aquelas teorias que permitem uma experiência crítica crucial e abandoná-las quando forem contraditas por tal experiência, momento em que será abonado seu caráter empirista.

\section{OS LIMIIES DA CORRESPONDÊNCIA}

O problema da racionalidade da ciência e sua relação com a verdade foi proposto por Popper, sob a influência de Tarski ${ }^{7}$ e pode ser expresso do seguinte modo: como podemos saber da correspondência ou não entre o conhecimento e

\footnotetext{
${ }^{6} \mathrm{O}$ debate sobre a capacidade e os limites das teorias pode ou não considerar os teoremas do austríaco Kurt Gödel (1906-1978). A falsificabilidade das proposições teóricas proposta por Popper implica essa consideração, pois, para ele, é no universo da linguagem, da argumentação, que ocorre o sentimento de crença por parte dos membros da comunidade científica. O primeiro teorema da incompletude de Gödel afirma que nenhum sistema consistente de axiomas cujos teoremas podem ser listados por um procedimento efetivo é capaz de provar todas as verdades sobre as relações dos números naturais, então, para qualquer sistema desse tipo, sempre haverá declarações sobre os números naturais que são verdadeiros, mas que não são prováveis no sistema. O segundo teorema mostra que esse sistema não pode demonstrar sua própria consistência. Isso é relevante argumentativamente no universo de referência em que a ciência atua.

${ }^{7}$ Alfred Tarski defendeu uma concepção semântica da verdade à luz da qual Popper concebeu sua concepção de verdade correspondencial. Já faz tempo que há grande debate sobre a legitimidade e conveniência da tese popperiana.
} 
seus objetos referidos se o que afirmamos tem princípios fixos e o mundo é dinâmico? Kant propôs que se concebesse uma mesma natureza e uma mesma experiência, abordadas por duas óticas distintas, a da razão e a do entendimento, responsáveis por dois tipos diferentes de leis e de conhecimentos. Popper concorda que há uma só natureza, entretanto, privilegiou a primeira ótica kantiana, a da razão e, reinventou a segunda, a do entendimento. Por consequência, só concebeu um tipo de lei e um tipo de conhecimento, além disso, seu ceticismo predominou, afirmou que não há episteme, somente doxa. Contrariamente ao empirismo tradicional, Popper admite as regularidades dos eventos do mundo como fato metafísico; assim, alcançou unidade ontológica, aos moldes de Frege, para quem não há o inteligível e o sensível, o puro e o empírico, o analítico e o sintético.

É um fato que as ideias puramente metafísicas - e, portanto, as ideias filosóficas - têm-se revelado da maior importância para a cosmologia. De Tales a Einstein, do atomismo antigo às especulações de Descartes acerca da matéria, das considerações de Gilbert, Newton, Leibniz e Boscovic, a propósito das forças, às de Faraday e Einstein, a respeito de campos de forças - a metafísica sempre indicou rumos (POPPER, 1974, p. 540).

O realismo científico clássico buscou estabelecer a correspondência das proposições aos fenômenos, observou os princípios de não contradição e de causalidade, assim como a suposição racional da inteligibilidade do mundo. O realismo de Popper, por sua vez, deflacionou os princípios e concebeu que se uma teoria testável de modo independente for verdadeira ela terá sucesso preditivo, entretanto, esse sucesso não constitui evidência da verdade. Isto porque a verdade é ideal regulativo e, assim, necessária à previsibilidade; é a priori, transcendental, de caráter intersubjetivo e regulativo; é o princípio ordenador e fio condutor responsável por dar sistematicidade à ciência e permitir a relevância teórica aos resultados da investigação. Para Popper, o entendimento é a articulação branda em uma interdependência sistêmica entre as proposições, de forma a constituir uma rede teórica capaz de ser suficientemente seletiva e apreender o objeto de investigação sem querer abarcar a totalidade do mundo, mas deve ser capaz de sustentar a inevitável imbricação entre todos os conteúdos racionais.

Uma vez que a verdade diz respeito ao uso descritivo da linguagem, enquanto a ideia de validade diz respeito ao uso argumentativo da linguagem, emitir um enunciado científico implica extrapolar em muito a experiência, pois uma descrição ocorre com nomes, símbolos e ideias universais, portanto, se insere no âmbito da validade. Deste modo, a correspondência é sempre correspondência lógica entre enunciados pertencentes a diferentes níveis de universalidade. Distintamente das sentenças protocolares que pretendiam enunciar experiências pessoais - como Carnap compreendeu -, em Popper, os enunciados básicos são concebidos como passíveis de teste. Ele afirma que, "de modo geral e especialmente [...] em casos críticos", nos detemos a enunciados facilmente suscetíveis de testes e não, como recomenda Carnap, em sentenças protocolares ou de percepção (POPPER, 2002a, p. 74). 
A despeito de o problema da base empírica ter-se ressentido severamente da confusão entre psicologia e lógica, segundo Popper, Fries "ensinou que, se não cabe aceitar por 'dogmatismo' os enunciados da ciência, devemos ter como justificá-los” (2002a, p. 75). Se exigirmos justificação através de argumentos que desenvolvam razões, no sentido lógico, seremos levados à concepção segundo a qual, enunciados só podem ser justificados por enunciados. Tal "predileção por demonstrações", todavia, tende a conduzir à "regressão infinita". Por outro lado, evitar o dogmatismo e o regresso ao infinito implica aceitar o "psicologismo". Diante do trilema - dogmatismo versus regressão infinita versus psicologismo -, Popper julgou necessário relativizar os enunciados básicos para solucioná-lo e se posicionou da seguinte forma: 1) a espécie de dogmatismo, presente na decisão de aceitar como satisfatórios determinados enunciados básicos, é inofensiva, visto que sempre se pode submeter tais enunciados a novas provas; 2) a potencial regressão infinita, decorrente dessa decisão, é inofensiva, pois, em teoria, não se pretende provar, de nenhuma forma, qualquer enunciado; 3) o psicologismo, presente na decisão de aceitar enunciados básicos, é inofensivo, uma vez que, não se trata de justificar enunciados com experiências: as experiências "podem motivar uma decisão" de aceitar ou rejeitar um enunciado, pois não existem razões positivas; só a crítica é racional (POPPER, 2002, p. 87). De um lado, o investigador está condenado a refazer sua ação sucessiva e infindavelmente, semelhante a Sísifo. De outro, ao contrário de Sísifo, o trabalho científico não é inútil e sem esperança de progresso. Trata-se de crer na suposição de inteligibilidade humana acerca da natureza e no princípio regulativo de que há a verdade. Assim, a ontologia orientadora da teoria do conhecimento popperiana terá um telos indeterminado, uma vez que a verdade é inatingível. Popper define a crença científica como uma aposta de que o procedimento objetivo tenha sucesso e, como crença subjetiva que ela é, se trata de crer que pode haver explicações objetivas. Tanto a demonstração lógica quanto o teste empírico são não conclusivos para estabelecer a correspondência entre as proposições e seu conteúdo. Assim, a perspectiva deste escrito é argumentar que a coerência é mais adequada à filosofia de Popper do que a correspondência, uma vez que os testes são críticos e ocorrem no universo da argumentação e não da descrição.

\section{O RACIONALISMO COERENTISTA}

Aqui trataremos de explicitar a verdade coerentista como a concebemos e, então, argumentar que a coerência se coaduna melhor com o novo empirismo falibilista popperiano do que a correspondência. Mostrar-se-á que o embate de Popper com o Círculo de Viena constituiu condições melhores à concepção de verdade coerentista do que à correspondencialista.

Apesar de a razão, para Popper, ser crítica e, assim, não haver base sólida aos moldes da proposta de fundamentação última do conhecimento na razão, de

\footnotetext{
${ }^{8}$ Psicologismo na definição de Popper é a doutrina de acordo com a qual enunciados podem encontrar justificação não apenas em enunciados, mas também na experiência perceptual.
} 
Descartes (2013) ele sintetizou metaforicamente sua concepção de base empírica, ${ }^{9}$ com a falseabilidade. O percurso de sua exposição pode ser assim descrito: a) nomeia enunciados básicos ou proposições básicas aos enunciados que podem atuar como premissas em falsificações empíricas; b) nomeia enunciados de fatos singulares que podem ser arrolados à argumentação como evidência para a falsificação de teorias; c) considera que enunciados só podem ser logicamente justificados por enunciados; d) enfrenta o problema de que uma teoria científica é uma proposição sintética e universal, sendo, por isso, inverificável; alcança uma compreensão mais complexa quanto ao problema do acesso à empiricidade: as sentenças de base são inferidas a partir das teorias. Popper entende que é possível solucionar tal dificuldade separando os aspectos psicológicos do problema, de seus aspectos lógicos e metodológicos, por isso, distingue, de uma parte, nossas experiências subjetivas ou nosso sentimento de convicção, que, segundo ele, jamais podem justificar qualquer enunciado e, de outra parte, as relações lógicas objetivas que se manifestam entre os vários sistemas de enunciados racionais e dentro de cada um deles (POPPER, 2002, p. 21). Para o programa da ciência unificada $^{10}$ do Círculo de Viena - a que Popper contesta por seu caráter verificacionista - questões acerca dos pressupostos incontornáveis e sobre o que ocorre quando o pesquisador afirma haver observações elementares, são tanto ociosas quanto insolúveis. A base é parte decisiva para um programa epistêmico empírico das ciências, mas a lógica do sistema científico de sentenças não deve estar em contradição. Na base somente há sentenças elementares que referem diretamente as entidades físicas, a partir das quais todo o resto se constrói. Essas sentenças de base fornecem o conteúdo empírico sob o título de protocolo, o que faz com que "todo o complexo de problemas fundamentais da teoria do conhecimento tradicional se dissolva na determinação lógica da base sobre a qual o estático sistema da ciência deve ser construído" (BUBNER, 1973, p. 134).

Contrariamente à posição verificacionista adotada pelos positivistas do Círculo de Viena, Popper inverte o sistema das ciências do positivismo e, aproximando-se de uma postura cética, afirma: "minha resposta às perguntas 'como sabes?' 'Qual a fonte ou a base da tua afirmativa?' Seria: 'não sei; minha afirmativa é simplesmente uma opinião. Não importa sua fonte - ou fontes; há muitas fontes possíveis e posso não ter consciência de uma boa parte delas [...] se puderes conceber um teste experimental para refutar o que eu disse, terei satisfação em te

\footnotetext{
${ }^{9}$ Em um adendo de 1968 à The logic of scientific discovery, Popper explica a antiga posição: ele afirma que a palavra "base" foi usada em um tom irônico, ou seja, a base não é fundamento, ela vacila.

${ }^{10} \mathrm{O}$ positivismo lógico ou neopositivismo tinha em seu programa três pontos principais: 1 . A ciência deve poder ser unificada na sua linguagem e nos fatos que a fundamentam, bem como todo conhecimento científico vem da experiência e do caráter tautológico do pensamento. 2. A filosofia se reduz a uma elucidação das proposições científicas e estas se referem direta ou indiretamente à experiência. A ciência tem por tarefa verificar tais proposições. A filosofia será, antes de tudo, filosofia da ciência. 3. O sucesso de tal filosofia porá fim à metafísica, pois não será mais necessário tratar "questões filosóficas", já que toda questão será tratada, agora, em uma linguagem provida de sentido. As questões tradicionais da metafísica serão questões que falarão apenas sobre termos dos quais o sentido não foi suficientemente esclarecido ou sobre proposições inverificáveis. (https://www.maxwell.vrac.puc-rio.br/9607/9607_4.PDF, certificação digital 0511058/CA)
} 
ajudar a refutá-lo" (POPPER, 2002a, p. 35). Assim, para Popper a base não é a garantia para um estático sistema teórico, apesar de constituir uma instância objetiva de referência para a falsificação de proposições universais.

Enquanto para os positivistas as proposições de base são a garantia de empiricidade e fundamento ao edifício lógico do conhecimento científico, para Popper, a especulação, inclusive metafísica, é instância constituidora das conjecturas que devem ser submetidas à lógica da pesquisa com a finalidade de estabelecer sua sistematicidade, instância em que a falsificação é critério decisivo. A importância das proposições de base não está na garantia de um conteúdo empírico para um sistema de sentenças fisicalistas, mas sim na função crítica que ela assume no respectivo processo de pesquisa. Proposições de base não são logicamente distintas, elas ganham importância, segundo sua potencial contribuição para o exame crítico de hipóteses em debates, no âmbito da comunidade científica.

O procedimento teórico que considera as experiências perceptuais como base empírica incide, segundo Popper, em psicologismo, uma vez que há a redução das ciências empíricas a percepções sensoriais e, assim, as nossas experiências constituem uma forma de dogmatismo, pois, o crédito ou descrédito às percepções sensoriais decorre da aceitação ou não da lógica indutiva. Ao definir sua posição em relação à concepção de ciência que privilegia a percepção sensorial, Popper afirma: "aqui a rejeitamos, porque rejeitamos a lógica indutiva" (POPPER, 2002, p. 74). Do ponto de vista epistemológico é, portanto, irrelevante o pouco de verdade que há na afirmação de que a matemática e a lógica se sustentam no pensamento enquanto as ciências factuais se fundamentam em percepções sensoriais. Mais importante do que isso é o fato de que sua postura se situa em um novo empirismo que vence o dogmatismo por substituir a ideia da experiência - observação - pelo exame crítico objetivo e a experienciação observabilidade - por uma testabilidade objetiva que tem lugar no universo da linguagem e é impregnado de teorias. Não existem observações puras, os enunciados básicos são enunciados objetivos, passíveis de crítica, e as hipóteses são transcendentes, tais como os enunciados universais.

Se o conhecimento deve corresponder ao seu conteúdo e toda a referência é teórica e não empírica; se a realidade somente pode ser apreendida por essas representações proposicionais; se a crença na realidade independente é somente metafísica, então, não transpomos nunca o abismo entre linguagem e mundo, entre palavra e coisa. Assim, a coerência argumentativa, a disposição à crítica e a pretensão de ampliar a compreensão cosmológica sobre o ordenamento do mundo se coadunam melhor com uma concepção de verdade coerencialista do que correspondencialista. Em nossa interpretação, foi problemática a reconstrução que Popper fez da concepção semântica da verdade para sua concepção correspondencial da verdade. Parece-nos que ele perdeu a oportunidade de coadunar melhor sua epistemologia com a concepção coerencialista da verdade sem macular seu adequado falibilismo, pois, no âmbito da argumentação crítica não há hierarquia. Qualquer proposição pode, a qualquer tempo, ser mostrada falsa. 
Defendemos que no âmbito da teoria coerentista pode-se pensar tanto naquilo que é objeto da crença quanto nas entidades portadoras de valor de verdade. Assim, segundo Schmitt (1995, p. 89) uma determinada proposição é verdadeira se, e somente se, é coerente com um conjunto específico de proposições. Também em Davidson (1991, p. 332), para quem "a maior parte das crenças de um conjunto total de crenças coerentes é verdadeira”, em sua discussão sobre a correspondência e a confrontação, fica claro que a correspondência de uma proposição com determinados fatos referidos decorre da coerência dessa proposição com um conjunto maior de proposições que referem esses mesmos fatos. Nestes termos, se eu receber a informação de que há seres humanos em Plutão, recusar-me-ei a considerar verdadeira a informação baseado no meu referencial teórico sobre as condições atmosféricas de Plutão, por considerar incoerente com um conjunto de outras proposições que manifestam crenças consideradas verdadeiras. Quando a informação recebida guardar coerência com um conjunto de crenças consideradas empiricamente verdadeiras, também ela será considerada verdadeira. A coerência não produz mais do que certa probabilidade de correspondência; na medida em que não forem confrontadas com a realidade, as condições de verdade de uma proposição são outras proposições, e não condições objetivas do mundo. Racionalmente temos que admitir a impossibilidade em transpor o conjunto das nossas teorias e confrontar uma ou um conjunto delas com a realidade. Essa admissão remete à impossibilidade de alcançarmos diretamente a correspondência entre o conhecimento e seu conteúdo. Ficamos, assim, com a coerência como indicadora da verdade. Podemos sustentar objetivamente que há coerência entre as proposições relativamente ao que afirmam sobre a realidade e que, por isso, são verdadeiras. O abismo não pode ser transposto, a ponte correspondencial se mostrou uma miragem. A coerência guarda o falibilismo e a objetividade sem pretender correspondência entre proposições e seu conteúdo, uma vez que este é igualmente expresso em proposições. Assim, a coerência é a melhor resposta epistemológica por tornar possível decidir sobre a verdade confrontando proposições no âmbito da crítica racional.

\section{A IRRELEVÂNCIA DA DEMARCAÇÃO}

Se o que importa a qualquer homem de razão é conceber uma cosmologia para entender a constituição e interdependência de todos os elementos do mundo, qual a importância da demarcação entre o que é científico e o que não é? A criatividade e a crítica é que são definitivas ao conhecimento. Apesar de Popper saber bem disso, perseguiu a demarcação como tarefa autoatribuída por força do seu apego aos temas do positivismo. Segundo ele, entretanto, Einstein foi o mais importante cientista para sua teoria do conhecimento, entre outros ele acreditou na razão crítica e na verdade, apesar de não ter feito distinção entre ciência e metafísica.

Einstein buscou a verdade, e pensou ter razões - razões críticas - que lhe indicavam que não a tinha encontrado. Ao mesmo tempo, deu, ele e muitos outros, razões críticas que indicavam que tinha feito grandes progressos na direção da 
verdade - que suas teorias resolviam problemas cujas respectivas antecessoras não eram capazes de resolver (POPPER, 2000, p. 26).

É com esse mote que superamos o estágio do debate até aqui apresentado. Segundo Bartley III a demarcação não é importante e constitui impeditivo à crítica racional, o relevante na tarefa de fazer aumentar nosso conhecimento é que se existam muitas teorias e que elas se enredem de tal forma que o jogo cognitivo possa ser imaginativamente rico e altamente crítico. Aquelas teorias, entretanto, que guardam estratagemas para não serem falsificadas, não devem ser tratadas como passíveis do crítério de demarcação. Antes de distinguir teorias científicas de não científicas dever-se-ia distinguir entre teorias críticas e não críticas. W.W. Bartley não acredita que haja critério eficiente para distinguir ciência e metafísica; sua tese é de que quando Popper afirmou que é a distinção entre a ciência empírica e os sistemas metafísicos que permite uma caracterização adequada da ciência, ele estava errado. Popper afirmou que um sistema de enunciados não falseável é desinteressante tanto para a ciência quanto para a crítica da ciência, entretanto, Bartley III afirma que um sistema de enunciados não falseáveis pode ser de grande interesse para o cientista empírico e para a crítica aos enunciados da ciência. A divergência entre um e outro é exatamente quanto à falseabilidade como critério de demarcação. A proposta de Bartley III é substituir a falseabilidade pela familiaridade, uma vez que, "o crítério de falseabilidade não informa se um dado sistema de enunciados merece o rigoroso estudo da ciência empírica. A descrição de Popper do interesse peculiar dos cientistas é simplesmente incorreta" (1968, p, 46). Segundo o autor, a falseabilidade é um critério lógico herdado às avessas do círculo e que não serve para demarcar.

Entendemos que a familiaridade exige a habilidade do cientista em jogar com grande quantidade de informações, de tal forma que possa constituir fomento à imaginação, à intuição, o que implica a cosmologia. Esta é uma tese compatível com a teoria popperiana e, podemos afirmar, é uma consequência legítima de seu pensamento, a questão a ser ainda considerada é quanto à ênfase a ser atribuída à falseabilidade ou à familiaridade. A importância que vemos na noção de familiaridade proposta por Bartley III é que impõe um aumento significativo do grau de problematicidade, de criticabilidade, relativamente ao problema da testabilidade, que denuncia certo resquício do empirismo positivista. Além disso, a familiaridade tem grande compatibilidade com a metafísica racional, a ética, a filosofia, a ciência e mesmo a arte. Nosso apoio à tese da familiaridade como elemento de grande interesse à ciência não é incondicional, é complementar e não substitutiva à falseabilidade na tarefa de desvendar as configurações cosmológicas do mundo, entretanto, no que se refere estritamente à possibilidade de crítica, é necessário considerar inapto ao pensamento racional o conjunto das proposições não criticáveis. Do ponto de vista das ciências o dogma é falso. 


\section{UMA CIÊNCIA À DERIVA}

Para Hume, a suposição indutiva é tanto indispensável como injustificável. O jovem Popper pensou ser dispensável e injustificável; Lakatos, ${ }^{11}$ por sua vez, entendeu desejável certo indutivismo na constituição das ciências, mesmo que injustificado. Popper, com sua verossimilitude, incidiu involuntariamente em indução - como apontou Watkins ${ }^{12}$ - e com isso legitimou Hume. Ele compreendeu que a crítica aos erros identificados move a reformulação da linguagem em pleno uso e, deste modo, compatibilizou sua posição com Neurath ${ }^{13}$ para quem é impossível que nosso projeto intelectual seja reformulado de uma vez por todas, ou que definamos a priori a direção a que a civilização deve seguir. Isso implicaria sabermos de forma definitiva como fazer e aonde chegar, mas essa alternativa não existe em ciência e filosofia, como afirma Popper: "Temos que reformar a linguagem ordinária enquanto a usamos, como foi dito por Neurath em sua metáfora do navio que temos de reconstruir enquanto tentamos manter-nos a seu bordo" (POPPER, 1979, p. 61).

No estrito interesse de propor o entendimento daquilo que é mais relevante para a atividade de produção de conhecimento racional, é impossível deixar de salientar que a noção de aproximação à verdade poderia ser expressa como sinônimo de afastamento do erro. Nesse caso, o problema que se coloca é o de investigar se é legítima a tese de que a verdade é a ideia reguladora e orientadora da atividade teórica ou se a crítica é que exerce essa função. Para Popper "a crítica racional é, na verdade, um meio através do qual aprendemos, crescemos em conhecimento e nos transcendemos a nós mesmos" (1979, p. 27). Popper percebeu seu fracasso quanto à proximidade da verdade, então refez o universo epistemológico e propôs a verdade como recurso metodológico crítico, não como atributo das teorias, e afirmou: "O uso de padrões tais como a verdade e a aproximação da verdade só desempenham papel dentro de nossa crítica” (1979, p. 266).

\footnotetext{
11 Lakatos (1974) traz um capítulo em seu livro Popper on demarcation and indution, com o título "Um apelo a Popper por uma brisa de indutivismo". Ele estava preocupado com o aumento da verossimilhança das ciências e um princípio de indução poderia articular a dinâmica da ciência e o crescimento do conhecimento, vinculando verossimilhança e corroboração, ao mesmo tempo diferenciando a proposta popperiana do ceticismo.

${ }^{12}$ Em substituição aos critérios de Popper para comparar graus de falsificabilidade, Watkins oferece a ideia de contrapartida e a noção de contrapartidas incongruentes que criam as condições para a contestação da ideia de verossimilhança (WATKINS, 1984, p. 30).

13 Neurath cria uma metáfora que é a seguinte: "Imaginem-se marinheiros que, em alto mar, transformam a forma mais circular do seu tosco navio numa forma mais aparentada à de um peixe. À parte a madeira da antiga estrutura, eles utilizam pedaços de madeira à deriva para modificar o esqueleto e o casco do navio. Mas não podem atracar o barco numa doca para começar do zero. Durante o seu trabalho, eles estão sobre a antiga estrutura lidando com fortes tempestades e estrondosas ondas. Ao transformar o barco, procuram evitar a ocorrência de infiltrações perigosas. Um novo barco surge do antigo, passo a passo - e enquanto ainda estão a construir, os marinheiros podem estar já a pensar numa nova estrutura e nem sempre concordarão uns com os outros. Tudo isto acontecerá de um modo que hoje não podemos sequer prever. É este o nosso destino" (NEURATH, 1944, p. 47).
} 
A aproximação da verdade não é definível sem indução, logo, não se sustenta racionalmente, como Hume apontou. A verdade não é mais guia, é critério para a crítica, a lógica, por sua vez, é a arma dessa crítica. Popper resolve o conflito entre a lógica normativa e a explicação factual em uma tese naturalista do conhecimento humano: as crenças que guiam os homens de ciência não são científicas, são metafísicas, constituem um ato de fé de que existem leis e de que elas possam ser conhecidas.

Diferentemente de suas obras da juventude, ${ }^{14}$ em sua maturidade Popper confessa já não crer mais em grande diferença entre conjecturas científicas e metafísicas, ${ }^{15}$ pois, segundo julga, há similaridade quanto à possibilidade de a crítica racional incidir sobre uma e outra das construções teóricas. Ele entende que a ciência necessita tanto de uma como de outra, uma vez que elas determinam em grande medida a situação de seus problemas. Há, portanto, uma ontologia no âmbito metafísico, responsável por subsidiar a epistemologia na esfera do conhecimento objetivo, científico. A antiga demarcação radical entre ciência e os demais saberes, a que Popper atribuiu importância quando jovem fica relativizada e, assim, permite a ideia regulativa da verdade como constituindo a centralidade referencial para toda sua epistemologia. Tal ontologia é também falibilista ao distinguir as metafísicas criticáveis daquelas em que a crítica é impossível.

Popper foi contraditório ao negar a indução e retomá-la em sua ideia de aproximação da verdade; foi superficial ao não relacionar sua teleológica ideia regulativa da verdade ao indeterminismo; foi ingênuo ao conceber a base empírica como decisiva em um falibilismo restrito, quando poderia ter transitado para uma concepção de verdade coerentista ${ }^{16}$ e falibilista, assim teria compatibilizado seu sistema. Entretanto, ele aceitou seus erros e os corrigiu parcialmente ao propor a verdade e a aproximação da verdade, assim como os testes empíricos como parâmetros para a crítica e aceitou que a apreensão teórica do mundo só é possível por representações na linguagem. Assim, venceu o positivismo e as teses antiliberais substituindo a fundamentação pela crítica em um universo cujas contradições teóricas são inevitáveis e o pluralismo conjectural permite desvendar mais amplamente a realidade. Seu instrumental conceitual pós-positivista permite

\footnotetext{
${ }^{14}$ Nessa época ele entendia que as crenças que guiam os homens de ciência não são científicas, são metafísicas, apesar de serem biologicamente explicáveis, constituem um ato de fé de que existem leis e de que elas possam ser descobertas, conhecidas. Sem tal crença não haveria investigação, mas a investigação jamais justificará essa crença. Há aí uma característica importante da tese popperiana, ela implica a metafísica em seu sistema mantendo a distinção radical da ciência. Ele produziu o que chamou de uma visão ampla do quadro da ciência e da sua pesquisa: "o que eu tenho em mente não é um quadro da ciência como um fenômeno biológico, instrumento de adaptação ou método indireto de produção - o que tenho em mente são os aspectos epistemológicos da ciência" (POPPER, 2002, p. 278).

15 "Eu já não creio, como acreditei por certo tempo, que haja diferença entre a ciência e a metafísica neste ponto tão importante. Considero que uma teoria metafísica é similar a uma científica. É mais vaga, sem dúvida e inferior em muitos outros aspectos e sua irrefutabilidade ou falta de contrastabilidade é o maior vício. Entretanto, como uma teoria metafísica pode ser criticada racionalmente, eu me inclinaria a respeitar seriamente sua implícita pretensão a ser considerada, tentativamente, como verdadeira" (POPPER, 1982, p. 199).

16 Sintética e formalmente pode-se dizer que a concepção coerentista da verdade consiste na seguinte formulação: Uma proposição $\mathrm{P}$ é verdadeira se, e somente se, é coerente com um conjunto especificado (C) de proposições.
} 
a interpretação objetiva do conhecimento relacional - altamente dinâmico, complexo e criativo -, acerca de uma realidade indeterminada, somente capturável na dimensão de sua mudança. $O$ interacionismo dos três mundos ${ }^{17}$ - físico, subjetivo e objetivo - é causal, assim, o indeterminismo metafísico é compatível com uma teleologia dinâmica aleatória, cujas propensões são sua ocorrência.

\section{ONTOLOGIA RELACIONAL E COERENTISMO FALIBILISTA}

A atividade argumentativa implica situar-se no âmbito do compromisso com a coerência. No campo teórico coerentista, as sentenças são pertinentes se pertencentes a uma rede em que os conceitos estabelecem a relação de interdependência e relevância de cada uma delas e, assim, são avaliadas quanto a sua validade argumentativa.

A atividade descritiva implica situar-se no âmbito do compromisso com a verdade. Nesse campo teórico, segundo Popper, as afirmações objetivas têm a pretensão de estar em acordo com a disposição do mundo referido. Elas são avaliadas segundo os critérios da correspondência com o conteúdo empírico que enunciam e julgadas corroboradas quando não contraditas pela experiência.

Ocorre que Popper afirmou ser a experiência uma instância da crítica. A crítica objetiva é sempre levada a efeito enquanto uma atividade argumentativa comprometida com a coerência. A objetividade das teorias é que as tornam descrições criticáveis do mundo, logo, o critério de verdade não é a correspondência e sim a coerência. Também aqui o falibilismo deve ser preservado. Considerando que a experiência somente motiva uma decisão no âmbito da argumentação crítica, um raciocínio pode ser, ou não, uma argumentação verdadeiramente coerente, mas não pode ser uma descrição verdadeira por faltar a possibilidade de contrastação das proposições teóricas,

\footnotetext{
${ }^{17}$ Mundo um é o dos objetos físicos ou de estados materiais; o mundo dois é aquele dos estados de consciência ou de estados mentais ou, ainda, de disposições comportamentais para a ação, tratando-se de estados mentais ou episódios internos; o mundo três é aquele dos conteúdos objetivos de pensamento, especialmente de pensamentos científicos, poéticos e de obras de arte, tratando-se de conteúdos semânticos dos produtos simbólicos. É o mundo dos conteúdos lógicos de livros, bibliotecas, memórias de computador, etc. Os dois primeiros mundos são descobertos pelos seres humanos, estando, portanto, culturalmente pressupostos. Já o terceiro é criado e recriado pelos homens na medida em que estes propõem novas interpretações ou novos problemas. Praticamente todo o nosso conhecimento subjetivo, conhecimento do "mundo 2", depende do "mundo 3", isto é, de teorias formuladas linguisticamente. Somente o mundo três é especificamente humano. O autor diz que, se se deve partir do fato de que o conhecimento científico objetivo é conjectural, pode-se, então, procurar o que lhe é análogo no campo do conhecimento subjetivo. O método do conhecimento é o método de conjecturas ousadas, de tentativas engenhosas e severas para refutá-las. Assim, teorias confirmadas não existem, o que não foi refutado é que tem (caso tenha sido amplamente testado) a seu favor a assertiva de que seu conteúdo de verdade é maior do que o de sua predecessora e concorrente. Assim, ocorre maior aproximação da verdade, mas não a verdade. Epistemologia é a teoria do conhecimento científico e, enquanto tal, pertence ao mundo três, senão vejamos: o conhecimento científico é objetivo, conjectural e independente do sujeito; dele pode-se procurar o que lhe é análogo no campo do conhecimento subjetivo. O mundo três, na condição de produto da atividade humana, se assemelha às casas e ferramentas ou obras de arte. Assim, igualmente, a linguagem é produto da atividade humana e, portanto, a ciência, a filosofia e os demais conhecimentos são construções objetivas que, uma vez produzidas, continuam a ser o que são independentemente de serem utilizadas ou não pelos homens.
} 
mesmo as de base, com os objetos descritos. Por isso Popper afirmou que as teorias científicas permanecem conjecturais.

Quando Popper afirmou que todas as formas de investigação humana estão sempre subordinadas a um problema principal, o problema cosmológico, ele não supôs uma cosmologia descritiva, pelo menos não inteiramente, apesar de poder conter descrições como algumas das suas teses secundárias. Teses cosmológicas estabelecem legitimamente proposições que poderiam ser testadas, mas que, contudo, não foram contraditas pela experiência, proposições empíricas não refutadas como falsas. Assim, o critério de verdade correspondencial está presente na conjunção de visões cosmológicas só secundariamente, somente como instância não definitiva da argumentação.

Portanto, se é no ambiente da argumentação que ocorre todo o entendimento possível acerca do mundo - tendo a experimentação como parte de um momento em que são arroladas as evidências - que se tomam as decisões sobre o que pode ser aceito como sendo uma boa conjectura da realidade como um todo, então, nossas concepções cosmológicas somente se apoiam precariamente na experiência e, ainda, de forma negativa. Nestas condições, o critério de verdade que melhor responde à situação epistemológica é aquele que exige a compatibilidade entre as proposições que formam a visão unificada da totalidade do existente, ou seja, a coerência.

Uma proposta cosmológica será coerente ou incoerente se as teorias que a formam constituem uma visão de mundo articulada, ordenada e universal. Entretanto, se forem identificadas discrepâncias, contradições, inconsistências entre proposições equivalentes, ter-se-á que corrigílas ou refutá-las inteira ou parcialmente, pois o mundo não pode ser discrepante, já que ele é o objeto a ser conhecido; as teorias, contudo, podem. Somente uma rede teórica ordenada, abrangente e relacional pode consistir em uma cosmologia, pois somente um mundo ordenado objetivamente pode ser pensado como objeto dela.

Uma vez que o todo somente pode ser pensado e não pode ser conhecido, não podemos pretender descrever o mundo, quando muito, algumas de suas partes poderiam ser conjecturalmente descritas, nisso consiste a ciência. Quanto ao cosmos, especulamos e reunimos elementos da razão aos parcos elementos da experiência científica, formamos uma rede argumentativa que pode ser coerente ou incoerente, capaz de apreender ou não a realidade na medida da amplitude de sua malha. Quando a incoerência for criticamente apontada, fica evidente tanto a falibilidade como a falsificação objetiva da teoria. A esse procedimento segue-se a correção ou o abandono da conjectura sobre o mundo.

Assim, se Popper teve razão para discordar dos positivistas e deslocar a demarcação significativo/assignificativo para científico/não científico, também Bartley III teve razão ao deslocar a demarcação entre científico/não científico para racional/não racional. Nesse trabalho propomos deslocar a demarcação para criticável/dogmático. Fica evidente que nem Popper nem Bartley III captaram o que de mais relevante há sobre a compreensão e o entendimento da relação entre todas as informações que constituímos sobre o mundo em que vivemos e sobre 
nós próprios. Aqui abonamos a tese de que o relevante não é a demarcação, a distinção entre um e outro campo, seja ciência de não ciência, seja racional de não racional. A correção aqui proposta se orienta por uma racionalidade dinâmica, para a qual é a aptidão relacional que fornece os elementos à crítica, uma vez que as experiências constituem instâncias destas. Portanto, é em uma ontologia relacional, dinâmica e propensitiva, que a atividade racional ganha relevância por imprimir realidade objetiva ao referente do pensamento. A criticabilidade é consequêcia da insuficiência incontornável da atividade de constituição da coerência. Uma cosmologia decorre da coerência entre as manifestações linguísticas e sua consistência é inversamente proporcional ao sucesso da crítica, embora diretamente proporcional à sucetibilidade às críticas. Desta forma, do ponto de vista epistemológico, o conhecimento que julgamos ter, necessita estar expresso em proposições, ele corresponde ao conteúdo do amplo conjunto de proposições que atualmente entendemos imunes às críticas e que guardam coerência entre sí. Por esse motivo, não há cientificidade cosmológica, não se pode descrever o todo e menos ainda estabelecer com eficácia a distinção entre ciência e metafísica ou entre racional e irracional. Pode-se, contudo, distinguir a crítica do dogma e avançar na construção do entendimento científico das partes e o entendimento cosmológico do todo. Por essas razões propormos a ontologia relacional e o coerentismo falibilista.

\section{REFERÊNCIAS BIBLIOGRÁFICAS}

BARTLEY III, William Warren. Teorias da demarcação entre ciência e metafísica. In: LAKATOS, Imre; MUSGRAVE, Alan (eds.). Problemas na Filosofia da Ciência. Actas do Colóquio Internacional de Filosofia da Ciência, em Londres 1965, v. 3. Amsterdam: North-holland Publishing Company, 1968. p. 40-64.

BUBNER, Rüdiger. Dialektik und Wissenschaft. Frankfurt an Main: Suhrkamp, 1973.

DAVIDSON, Donald. Uma teoria coerentista da verdade e do conhecimento. In: CARRILHO, Manuel Maria; SÁÀGUA, João (orgs.). Epistemologia: posições e críticas. Lisboa: Fundação Calouste Gulbenkian, 1991. p. 327-360.

DESCARTES, René. Discurso do método. Lisboa: Edições 70, 2013.

HUME, David. A Treatise of human nature. Oxford: Oxford University Press, 1978.

KANT, Immanuel. Kritik der reinen Vernunft. Riga: Johann Friedrich Hartknoch de 1787. Transl. N. Kemp Smith. London: Macmillan, 1929.

LAKATOS, Imre. Falsificação e metodologia. Tradução Emília Picado Tavares Marinho Mendes. Lisboa: Edições 70, 1999.

Popper on demarcation and induction. In: SCHILPP, Paul Arthur (ed.). The philosophy of Karl Popper. La Sale/Illinois: Open Court, 1974.

NEURATH, Otto. Foundations of the Social Sciences. Chicago: The University of Chicago Press, 1944. 
POPPER, Karl. Die beiden Grundprobleme der Erkenntnistheorie. Aufgrund von Manuskripten aus den Jahren 1930-1933, hrsg. v. Troels Eggers Hansen. Tübingen: J.C.B. Mohr, 1979.

Quantum theory and the schism in physics. London and New York: Routledge, 1982. Realism and the aim of science. London and New York: Routledge, 2000. . The open universe. London and New York: Routledge, 2000a.

\section{2.} . The logic of scientific discovery. London and New York: Routledge Classic,

. Conjectures and refutations: the growth of scientific knowledge. London and New York: Routledge Classics. 2002a.

SCHMITT, Frederick F. Truth: a primer: Boulder/San Francisco/Oxford: Westview Press, 1995.

WATKINS, John W. N. Science and scepticism. London: Hutchinson, 1984. 